\title{
CAESAREAN SCAR ECTOPIC PREGNANCY: VARIED PRESENTATIONS WITH THEIR DIAGNOSTIC AND THERAPEUTIC IMPLICATIONS
}

\author{
Venus Bansal1, Niti Poonia², Kumkum Avasthi3 ${ }^{3}$ Kavita Srivastava ${ }^{4}$ \\ ${ }_{1}^{1}$ Senior Consultant, Department of Obstetrics and Gynaecology, SPS Hospitals, Ludhiana. \\ ${ }^{2}$ Senior Resident, Department of Obstetrics and Gynaecology, SPS Hospitals, Ludhiana. \\ ${ }^{3}$ Senior Consultant \& DNB Co-ordinator, Department of Obstetrics and Gynaecology, SPS Hospitals, Ludhiana. \\ ${ }^{4}$ Senior Consultant, Department of Pathology, SPS Hospitals, Ludhiana.
}

\begin{abstract}
BACKGROUND

Caesarean scar ectopic can be missed as a diagnosis resulting in catastrophic consequences for the patient. Here, we present three cases of scar site ectopic pregnancies, how they presented to us and how all were managed differently. The first patient presented to us in shock after a D and C was done outside for termination of pregnancy. It eventually turned out to be a scar site ectopic and as the patient was hemodynamically deteriorating a laparotomy was done in which hysterectomy had to be done due to massive intraoperative haemorrhage which was not controlled by conservative measures. The second case presented to us as a clearcut diagnosis of caesarean scar ectopic pregnancy. Laparotomy followed by excision of g-sac was done for her with minimal bleeding intraoperatively. The third case presented to us in shock, again after undergoing $3 \mathrm{D}$ and Cs outside for termination of pregnancy. As the patient got haemodynamically better and bleeding stopped, baseline beta-HCG was done and patient was given injection methotrexate to which the patient responded well.
\end{abstract}

\section{KEYWORDS}

Caesarean Scar Pregnancy (CSP).

HOW TO CITE THIS ARTICLE: Bansal V, Poonia N, Avasthi K, et al. Caesarean scar ectopic pregnancy: varied presentations with their diagnostic and therapeutic implications. J. Evolution Med. Dent. Sci. 2016;5(23):1267-1269, DOI: 10.14260/jemds/2016/296

\section{INTRODUCTION}

Following is a case series reporting 3 different clinical presentations of caesarean scar ectopic pregnancies and the different ways in which they were managed in our hospital.

\section{Case 1}

Pt. X, 28 years of age, G2P1LIA0 with previous LSCS presented to us in shock after D and E outside for irregular bleeding P/V since 45 days. Patient was not sure of her LMP? October 2013. She took emergency contraceptive pill over the counter after an unprotected intercourse in November. She tested positive for pregnancy at home on $25^{\text {th }}$ December, after which she took Medical Termination Pills (OTC). After that she persistently had bleeding P/V that continued for 45 days. She visited a private practitioner, where USG was done that showed retained products of conception. $\mathrm{D}$ and $\mathrm{E}$ advised and conducted on patient. During the procedure, patient had torrential bleeding for which vaginal packing was done and patient referred to our hospital.

On admission patient was in shock with PR-140/min, BP$80 / 40 \mathrm{mmHg}$ and RR-28/min. On P/A examination, suprapubic tenderness was present. Fresh blood was oozing from the pack through the vagina. After initial resuscitative measures, USG was done which suggested? Retained products of conception? Uterine perforation with normal uterine endometrial lining. Her Complete blood count, RBS, Kidney Function Test, Liver Function Test, Serum electrolytes, Coagulation profile and Viral markers were sent.

Financial or Other, Competing Interest: None.

Submission 25-01-2016, Peer Review 04-03-2016,

Acceptance 09-03-2016, Published 21-03-2016.

Corresponding Author:

Dr. Niti Poonia

N-33, Doctors Hostel,

Dayanand Medical College \& Hospital,

Ludhiana, Punjab.

E-mail: nitipoonia@gmail.com

DOI: $10.14260 /$ jemds/2016/296
$\mathrm{Hb}$ was $8.2 \mathrm{gm} \%$, platelets $1 \mathrm{lac} /$ cumm, rest of the investigations being normal. In view of above history, USG findings and patient continuing to bleed, decision of examination under anaesthesia and proceed was taken. High risk consent was obtained.

In OT, the patient was anaesthetised. Vaginal pack removed and per speculum examination done. Cervical external os was patulous and bleeding through os +++. On P/V examination, cervix was distended and uterus could not be made out. Throughout the procedure, fresh bleeding $\mathrm{P} / \mathrm{V}$ continued. Considering cervical pregnancy, cervical evacuation under USG guidance and cervical tamponade with pack and Foley's catheter tried, but bleeding still continued.

Resuscitative measures continued side by side. Patient's family counselled for bilateral uterine artery embolization, but refused. Laparotomy done that showed distended cervix of $8 \times 10 \mathrm{cms}$ with $1 \mathrm{~cm}$ perforation at the level of previous scar on the left end. No bleeding from the site of perforation present.

Bladder was densely adherent to previous LSCS scar and cervix. Same separated by sharp dissection and uterine arteries ligated bilaterally, but still bleeding continued. With consent of family, decision of hysterectomy taken and same completed. Specimen sent for histopathology. Postoperative, patient was fine. In histopathological examination, cut section of uterus revealed cervix distended with blood clots and a raw area (Attachment of pregnancy) with high vascularity was present on the scar of previous pregnancy. Cut surface of lower uterine segment appeared irregular.

Along with this $8 \times 8 \times 2 \mathrm{~cm}$ tissue pieces mixed with blood also received, which came out to be products of conception. Microscopic sections showed many chorionic villi with chronic ischemic changes and blood clots. Sections of uterus from scar site showed trophoblastic giant cells infiltration in endometrium and myometrium with chorionic villi areas (Figure 1 and 2). 
Case 2

Patient Y, 31-year-old, G4P3L3 with previous 1 caesarean section, presented at 9 weeks' gestation for medical termination of pregnancy in view of failed contraception.

An ultrasound was done before moving on to any further management and USG revealed a single live pregnancy of 9.2 weeks at previous LSCS scar with thinned out myometrium between decidual reaction of $\mathrm{G}$ sac and posterior urinary bladder wall suggesting a caesarean scar ectopic pregnancy. Patient was appropriately investigated and after a preanaesthetic check-up was taken up for surgery.

As medical management was not feasible, hysterotomy followed by evacuation of $\mathrm{G}$ sac followed by bilateral tubal ligation was done. Intraoperatively, the lower segment of the uterus was distended and bladder was adherent to anterior wall of uterus, which was separated by sharp dissection. There was minimal blood loss of about $200 \mathrm{~mL}$ during the entire surgery and post-operatively the patient remained stable and was discharged after 48 hours (Figure 3 and 4).

\section{Case 3}

Patient Z, 24 years old, G5P1L1A3, with previous 1 caesarean section and 3 spontaneous abortions was referred to emergency in view of torrential haemorrhage after a check curettage was attempted for retained products of conception. The patient had a dilatation and evacuation 15 days back in view of missed abortion, but was continuously bleeding per vaginum since then. Again D and C was done 7 days back for the same reason, followed by check curettage on the day of presentation to our emergency.

Patient arrived to us in shock and severe anaemia (hb$4.3 \mathrm{gm} \%$ ). After initial resuscitative measures an ultrasound was done which revealed a $4 * 3.7 * 3.3 \mathrm{~cm}$ size well-defined heteroechoic space-occupying lesion along anterior wall of uterus in lower uterine segment with caesarean scar ectopic and fibroid as being the differentials. As the patient was stable after the resuscitative measures and not actively bleeding, a baseline beta-HCG was sent which was 3353. B-HCG was repeated again after 48 hours and the values this time were 1600. As it was an involuting scar pregnancy and vitally patient was stable, Inj. methotrexate $50 \mathrm{mg}$ was given IM after performing a CBC, LFT and RFT. Patient was discharged and asked to come for followup on day 4 and beta-HCG at this visit was 900. Patient is on regular followup after this (Figure 5).

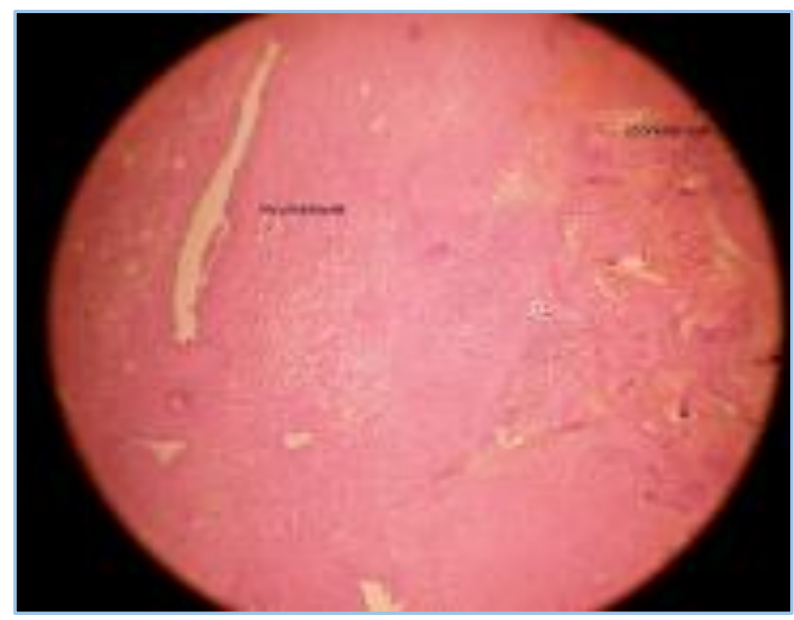

Fig. 1: Microscopic View of Chorionic Villi Invading the Myometrium

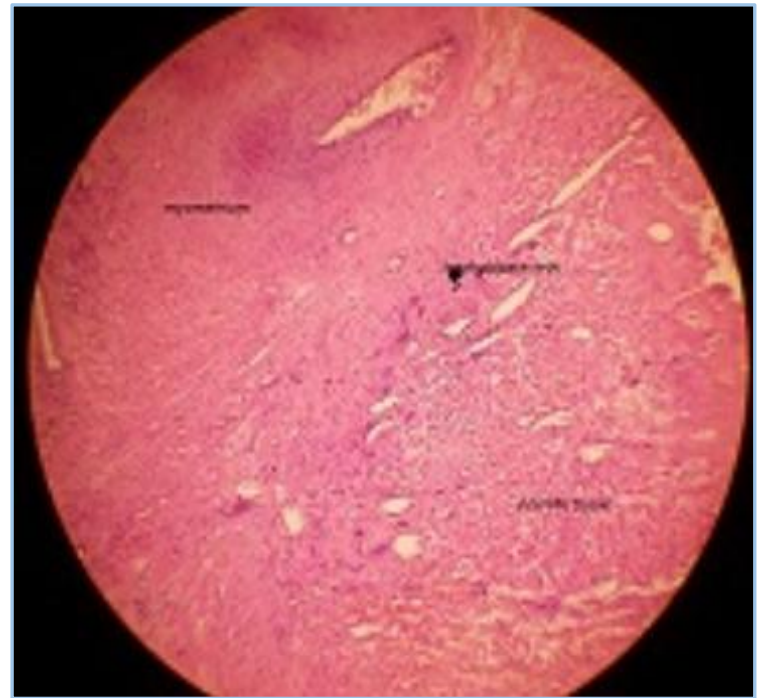

Fig. 2: Trophoblastic Cells in the Myometrium

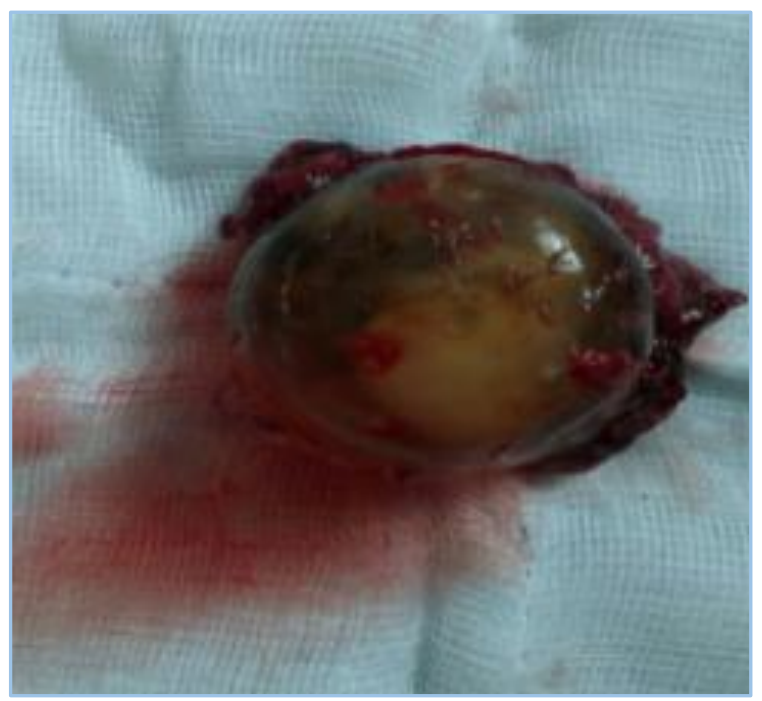

Fig. 3: Picture showing Entire GSAC Removed from Scar Site

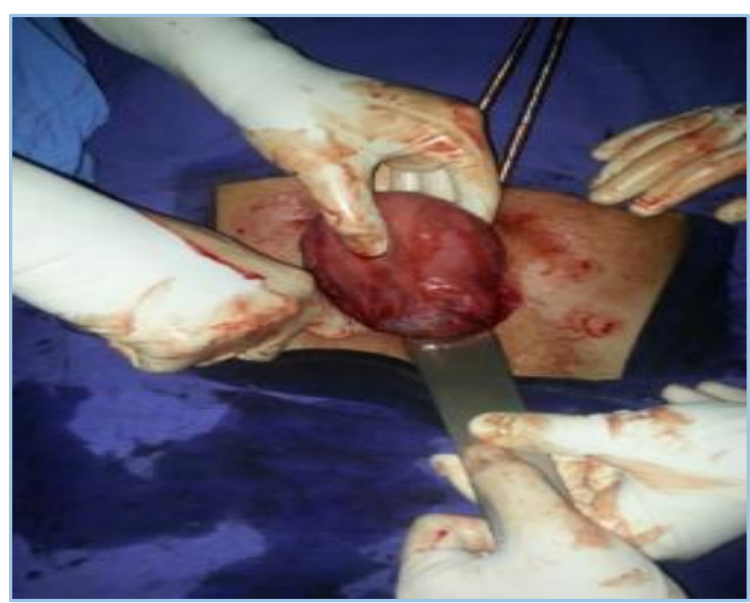

Fig. 4: Intraoperative Image showing Ectopic Pregnancy at Scar Site 


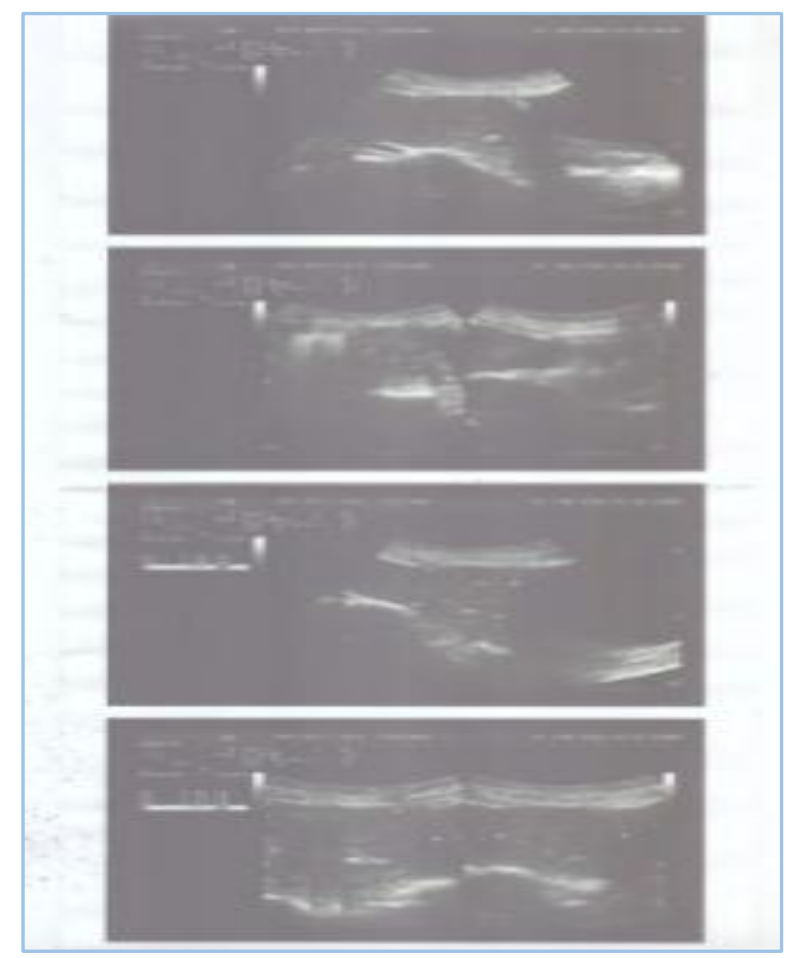

Fig. 5: USG Image of Scar Site Ectopic Pregnancy

\section{DISCUSSION}

All three cases detailed above were scar pregnancy with different presentations, diagnosis being missed in two of the cases on first visit at primary centre and all were managed in different ways.

Caesarean Scar Pregnancy (CSP), a pregnancy implanting within the scar from a previous caesarean delivery is a rare type of ectopic pregnancy. The incidence of CSP is $1 / 1800$ to $1 / 2216$ pregnancies. ${ }^{1}$ Because of the few cases reported, epidemiological analysis is somewhat limited. There are two different types of CSPs. Type I is caused by implantation of the amniotic sac on the scar with progression toward either the cervico-isthmic space or the uterine cavity.

It may progress to viable pregnancy with significant risk of haemorrhage. Type II (CSP-II) is caused by deep implantation into a previous CS defect with infiltrating growth into the uterine myometrium and bulging from the uterine serosal surface, which may result in uterine rupture. In our first and third cases, it is difficult to comment which type of CSP it was as it was distorted by D and C outside.

Diagnosis of CSP need high index of suspicion, as up to $40 \%$ can be asymptomatic. The most common symptom is painless vaginal bleeding, at times it can be massive. The diagnosis of caesarean scar pregnancy is made primarily using transvaginal sonography with a reported sensitivity of $84.6 \%$.

\section{The Sonographic Criteria for Diagnosis of CSP are:}

i. Empty uterus and empty cervical canal.

ii. Development of the sac in the anterior wall of the isthmic portion.

iii. A discontinuity on the anterior wall of the uterus demonstrated on a sagittal plane of the uterus running through the amniotic sac.

iv. Absent or diminished healthy myometrium between the bladder and the sac. v. High velocity (Peak velocity $>20 \mathrm{~cm} / \mathrm{sec}$ ) and low impendence (PI $<1$ ) waveform on Pulsed Doppler have been proposed with scar implantation.

The differentiating point between CSP and cervicoisthmical pregnancy is the absence of healthy myometrial tissue between sac and bladder.

Other authors have suggested that 3-dimensional ultrasound can aid in the diagnosis of caesarean scar pregnancy by improving delineation of the gestational sac and surrounding structures. ${ }^{2}$ Findings of magnetic resonance imaging may be helpful as an adjunct to TVS and Doppler in evaluating CSP when additional information needed to decide for medical or surgical management. ${ }^{3}$ MRI can be time consuming, so usually avoided in unstable cases. Beta HCG levels in blood follows the same pattern as other ectopic pregnancies.

Diagnostic criteria are altered in cases who have underwent some intervention earlier like $\mathrm{D}$ and $\mathrm{C}$ and medical termination pills.

There are no guidelines for managing the cases of CSP. The rarity of this entity results in a lack of consensus on optimal management. Treatment can be medical or surgical. Medical management is either local or systemic Inj. methotrexate or embryocide like KCL, hyperosmolar glucose, crystalline trichosanthin. Scar being a fibrous tissue with limited blood supply may be a reason for failure of systemic methotrexate therapy. Prerequisite for medical treatment is vital stability of patient. It requires prolonged followup, compliant patient, high cost and if fails surgery may be needed. The same was the reason for our patient to refuse for UAE. The surgical procedure, either by laparoscopy or laparotomy that can be done are,

i. Evacuation of the pregnancy and repair of the uterine defect (Hysterotomy).

ii. Dilatation and Curettage and excision of trophoblastic tissues.

iii. Bilateral uterine or hypogastric artery ligation associated with D and C.

iv. Uterine artery embolization with local methotrexate. ${ }^{4}$

v. Radical surgery, hysterectomy.

Although, UAE seems to be promising in treating stable cases, it is not recommended as a primary line therapy.

\section{REFERENCES}

1. Seow KM, Huang LW, Lin YH, et al. Cesarean scar pregnancy: issues in management. Ultrasound Obstet Gynecol 2004;23:247-253.

2. Pascual MA, Hereter L, Graupera B, et al. Threedimensional power doppler ultrasound diagnosis and conservative treatment of ectopic pregnancy in a cesarean section scar. Fertil Steril 2007;88(3):706.e5-7.

3. Rebecca Wu, Michelle A Klein, Sabrina Mehboob, et al. Magnetic resonance imaging as an adjunct to ultrasound in evaluating caesarean scar ectopic pregnancy. J Clin Imaging Sci 2013;3:16.

4. Yang XY, Yu H, Li KM, et al. Uterine artery embolisation combined with local methotrexate for treatment of CSP. BJOG 2010;117:990-6. 